\title{
PEDAGOGIA DA GESTÃO GERENCIALISTA DO CAPITAL: A "PAIDEIA" EMPRESARIAL DO FINAL DO SÉCULO XX E SUA HEGEMONIA IDEOCULTURAL NO SÉCULO XXI ${ }^{1}$
}

\section{Pedagogy of capital management management: the business "paideia" from the end of the 20th century and its ideocultural hegemony in the 21st century}

Iael de Souza ${ }^{2}$

Evaldo Piolli ${ }^{3}$

\begin{abstract}
RESUMO: O texto analisa os elementos constitutivos da pedagogia gerencialista do capital como uma expressão das formas renovadas do capital gerir seu projeto de dominação. Por um lado, esse projeto se expressa por um conjunto de reformas do aparelho estatal, em complemento a uma política de ajuste neoliberal ou de um neoliberalismo social de terceira via, representado, no campo educacional, pelos modelos de parceria público-privada, com a abertura para atuação das fundações e institutos empresariais. Por outro, esse movimento se expressa por concepção de formação da força de trabalho pela escola, impregnada pela lógica empresarial com o propósito de forjar e inculcar novos valores alinhados aos imperativos do mercado, dos capitalistas e do sistema metabólico do capital. Procuramos demonstrar como que a busca do consenso foi o elemento constitutivo fundamental da nova paideia e da hegemonia empresarial na agenda educacional, pautada pelos imperativos do mercado, da concorrência, da competitividade e pelas renovadas necessidades do capital que demanda um novo perfil de trabalhador.
\end{abstract}

Palavras-chave: Pedagogia gerencialista. Hegemonia empresarial. Formação da força de trabalho.

\begin{abstract}
The text analyzes the constitutive elements of the managerial pedagogy of capital as an expression of the renewed ways of capital managing his project of domination. On the one hand, the project is expressed by a set of reforms of the state apparatus, in addition to a policy of neoliberal adjustment or of a third-way social neoliberalism, represented, in the educational field, by the models of public-private partnerships, with the open action of business foundations and institutes. On the other hand, expressed by the conception of the formation of the workforce by the school, impregnated by the business logic with the purpose of forging and including new values aligned with the imperatives of the market, of the capitalists and of the metabolic system of capital. We seek to demonstrate how the search for consensus was the essential element of the new paideia and corporational hegemony in the educational agenda, guided by the imperatives of the market, competition, competitiveness and the renewed needs of the capital that demands a new worker profile.
\end{abstract}

\footnotetext{
1 O presente artigo é parte da tese doutoral defendida em fevereiro de 2020 no Programa de Pós-Graduação da Faculdade de Educação da Universidade Estadual de Campinas (UNICAMP), intitulada: A Pedagogia Gerencialista do Capital - Neoliberalismo, Empresariamento e Mercadorização da Educação "Pública"-Estatal (Fundação Lemann, Instituto Unibanco e Estado do Piani - 2003/2017), sob orientação do professor Dr. Evaldo Piolli.
}

2 Doutora em Educação pela Universidade Estadual de Campinas (UNICAMP). Professora efetiva do Curso de Licenciatura em Educação do Campo (LEdoC) e do Curso de Economia da Universidade Federal do Piauí (UFPI), Campus Ministro Petrônio Portella (CMPP), em Teresina (PI). E-mail: iaeldeo@gmail.com

${ }^{3}$ Doutor em Educação pela UNICAMP. Professor efetivo do Departamento de Políticas, Administração e Sistemas Educacionais (DEPASE) da Faculdade de Educação da UNICAMP. Pesquisador do Laboratório de Gestão Educacional (Lage) e líder do Grupo de Pesquisa Trabalho, Saúde e Subjetividade (NETSS). E-mail: epiolli@yahoo.com.br 
Keywords: Managerial pedagogy. Corporate hegemony. Training of the workforce.

\section{CONSIDERAÇÕES INICIAIS}

A Pedagogia do Capital é a manifestação da forma de condução das relações sociais e de produção capitalistas e, principalmente, do capital vivo, a força de trabalho, adquirindo formas diversas, conforme às necessidades postas e exigidas pelo processo de expansão e acumulação do sistema capital, que vai colocando novas e renovadas exigências, conforme as implicações do patamar alcançado e das contradições aguçadas em seu processo de reprodução pela intensificação da produção exponencial de riqueza e sua apropriação privada, cada vez mais concentrada e centralizada.

Na década de 1980, assiste-se ao alvorecer de uma nova forma, a da gestão (dominação) gerencialista (meios, técnicas, procedimentos, processos utilizados para o exercício da dominação e controle do e sobre o social). O conceito se espraia por todos os poros da vida social: não mais recursos humanos, mas "gestão" de pessoas; não mais administrar, mas "gerir"; aquele que comanda, que controla, que detêm o poder de planejar, não é mais um administrador, mas um "gestor" que "anima". Emula-se a crença que todos os problemas, sejam no âmbito que for (pessoal, profissional, privado, público), podem ser sanados através do gerencialismo da gestão ou da gestão gerencialista.

Se a década de 1980 principia esse movimento gestionário, fecundando a Pedagogia da Gestão Gerencialista e a Pedagogia Gerencialista, a década de 1990 a gesta e pare, e as duas décadas do século XXI faz delas a forma de condução hegemônica das relações sociais e de produção, da política "pública"-estatal do Estado (Capitalista e do Capital) e de controle do capital vivo (a força de trabalho em exercício e aquela ainda em preparação nos bancos escolares e demais instituições de ensino).

Logo, a expressão Pedagogia Gerencialista do Capital evidencia a forma renovada do sistema capital garantir sua dominação, ampliando os campos e áreas de influência e atuação das suas principais personas, os empresários e os homens de negócio, que, através das reformas infraconstitucionais do aparelho e aparato do Estado-Nação, mediante legalidade das Parcerias Público-Privadas, das Organizações Sociais, Organizações da Sociedade Civil de Interesse Público e outros meios jurídicos-políticos-administrativos afins, vão se apropriando de setores estratégicos da economia, como, por exemplo, o da Formação (educação) e reprodução (saúde, transporte, habitação) da força de trabalho da classe trabalhadora, vitais para o projeto político-social- 
ideocultural de homem, de sociedade e de mundo ("Uma Ponte para o Futuro", "Pátria Educadora"), servindo também, para aumentar seus lucros ao transformar o social em negócio, e o direito social em direito privado.

Por fim, há que se ressalvar que a Pedagogia da Gestão Gerencialista também é um complemento fundamental da implementação da política-econômica neoliberal, e, no caso brasileiro, do neoliberalismo social-liberal de Terceira Via, como demonstrado pelo coletivo coordenado por Neves (2005; 2010), porque o social-liberalismo (CASTELO, 2013), ao se apropriar das bandeiras de luta, conceitos e palavras de ordem dos progressistas e da dita esquerda, procura amenizar os efeitos colaterais extremamente pérfidos do neoliberalismo, além de fazer dos problemas sociais e da questão social mais um nicho de negócios para o terceiro setor, construindo as parcerias entre "público-estatal" e privado, privatizando o público e individualizando o que antes tinha como característica essencial à universalidade.

Procura-se, através da exposição e reflexão desenvolvidas, contribuir para desvelar qual seria a pedagogia e a paideia empresariais conformadas no século XX e os meios que permitiram a sua hegemonia ideocultural no século XXI, visando uma compreensão mais aproximada e adequada do movimento do real, a fim de que possamos nos munir e realizar formas de enfrentamento verdadeiramente eficazes no combate e superação do atual estado de coisas que contribuiu para o aprofundamento do processo de alienação e de estranhamento dos indivíduos sociais, ainda mais fortalecido e intensificado pela apropriação direta do empresariado e dos homens de negócio do aparelho ideológico por excelência do Estado Capitalista: as instituições escolares, responsáveis pela (re)produção dos valores, sentimentos, comportamentos, atitudes requeridos por cada época historicamente determinada e que, na atual, se volta para atender aos imperativos sistêmicos do mercado, dos capitalistas e do sistema sociometabólico do capital.

\section{A PAIDEIA EMPRESARIAL DO FINAL DO SÉCULO XX E SUA HEGEMONIA IDEOCULTURAL NO SÉCULO XXI}

Para os gregos, a paideia significava um alto conceito de valor, um ideal objetivo, consciente, e não um aspecto exterior da vida. Na paideia grega está presente a ideia de uma educação do homem, de acordo com a verdadeira forma humana, com o seu autêntico ser (ontologia). Não se pode evitar o emprego de expressões modernas como: civilização, cultura, tradição, literatura ou educação; nenhuma delas, porém, coincide realmente com o que os gregos entendiam por paideia. Cada um daqueles termos se limita a exprimir um aspecto daquele conceito 
global e, para abranger o campo total do conceito grego, teríamos de empregá-los todos de uma só vez. ${ }^{4}$

No final do século XX e início do XXI assiste-se ao ressurgimento do conceito, porém, sobremaneira aviltado e empobrecido, porque estreitado unilateralmente para servir à tradução do ethos empresarial e dos homens de negócio, reduzindo a multifacetariedade humana a características e requisitos padrões de um pensamento único, voltado para atender à lógica de mercado, da concorrência e competitividade, às renovadas necessidades da acumulação do capital, requerendo, como condição objetiva e subjetiva, um determinado perfil de homem e de trabalhador.

A preocupação passa a ser a criação e a sustentação das ideias que justifiquem e plenifiquem de sentido o novo modus vivendi e operandi da concorrência e da competição econômicas do neoliberalismo de mercado. É necessário pautar e nortear a flexibilização e a precarização das relações de trabalho em ideias e crenças aparentemente inquestionáveis, dado que têm ciência de que "são as ideias e as crenças que governam o mundo" (GEORGE, 2003, p. 95) e, justamente por serem mutáveis, necessitam ser lapidadas de tempos em tempos para continuar garantindo a dominação intelectual, moral e cultural sobre a produção do senso comum renovado.

Trata-se, de fato, da necessidade vital do sistema do capital e dos capitalistas de "modelar conscientemente a ideologia de modo que as ideias e crenças atualmente dominantes sirvam para justificar o grande projeto" (GEORGE, 2003, p. 96), contando, para isso, com um "quadro de pensadores, escritores, professores e comunicadores capazes de desenvolver conceitos, argumentos e imagens que resultem, nos planos intelectual, moral, econômico, político e psicológico, em estratégias enérgicas" de persuasão para o consentimento do social. "Esses intelectuais deverão, da mesma forma, elaborar e difundir uma ética inovadora e pragmática para o século XXI” (GEORGE, 2003, p. 98), soterrando o conhecimento humanista e de conteúdo por um saber instrumental e utilitário traduzido em competências e habilidades analíticas e socioemocionais.

É nesse sentido que se assiste ao avanço das Fundações e Instituições mantidas por empresários e homens de negócio sobre a agenda das políticas educacionais, com a finalidade de influir na formação da força de trabalho e na preparação daquela já inserida no mercado de trabalho, tanto formal quanto informal, e em suas variações de precarização, como a uberização. São novos métodos de conquista muito mais sutis e eficientes do que os tradicionais, que funcionam, basicamente, por meio da excelência da manipulação ideológica ideocultural e disseminação de uma nova paideia essencialmente empresarial, proporcionando uma nova hegemonia cultural, aliando “métodos indiretos de dominação pelo reforço dos ajustes estruturais" (GEORGE, 2003, p. 111).

${ }^{4}$ Ver Jaeger (1995, p. 03-20). 
Como sentencia George (2003, p. 111-112): “Os dominados (devem) ser incapazes de compreender a organização e os métodos de seus mestres e de se mobilizar contra eles".

Nessa empreitada de conquista e dominação, no Brasil, a burguesia (e suas várias camadas mutatis mutandis), detentora das grandes corporações e conglomerados produtivos, de serviços, industriais, agrícolas e financeiros, vai se arregimentando, mobilizando e organizando a partir da década de 1980, sendo um marco a criação do Instituto Liberal, em 1983, persuadindo outros empresários de "visão" a se juntar ao movimento de renovação da força empresarial e dos homens de negócio na consolidação do neoliberalismo social-liberal de Terceira Via à brasileira (modernização, desenvolvimento, produtividade, eficiência, meritocracia, responsabilização, inovação, adaptação e resultados). Aqui desponta o embrião do Todos pela Educação (TPE).

Ainda que no Brasil a materialização do pensamento neoliberal se dê pelo ideário políticoideocultural do Instituto Liberal em 1983, o ano anterior marca a ofensiva da nova direita a nível mundial, inibindo o welfare state dos países periféricos, conhecidos como "em desenvolvimento".

Os aparelhos privados de hegemonia empresarial também desenvolvem um trabalho de longa duração junto à sociedade civil, a fim de produzir o novo consenso que legitime a nova forma de dominação do privado sobre o público, onde o primeiro se torna sinônimo de qualidade, competência, produtividade, eficiência e modelo para uma gestão gerencialista de sucesso e bons resultados (ISO's; GIFE - Grupo de Institutos, Federações e Empresas; Programa Comunidade Solidária; Instituto Ethos de Empresas e Responsabilidade Social; Prêmio ECO; Fundações, Institutos, OS’s e OSCIP's da burguesia industrial e financeira etc.) a ser seguido pelo segundo, sua antítese, apresentando todos os adjetivos contrários ao privado.

Alguns dos resultados são aqueles demonstrados por Dardot; Laval (2016), por Laval (2004) e Gaulejac (2007). Embora os dois primeiros sejam foucaultianos e Gaulejac um sociólogo que organiza e desenvolve a Sociologia Clínica, ou psicossociologia clínica, os estudos por eles efetivados em relação à construção (da pedagogia) da gestão gerencialista, de sua hegemonia ideocultural e às implicações para a sociabilidade humana apresentam insights significativos que não só podem, como devem, ser utilizados para nossa reflexão.

Dardot; Laval (2016), assim como Laval (2004) são perspicazes ao identificar a gestão gerencialista da burguesia empresarial e dos homens de negócio como a nova ética do espirito do capitalismo, justificando e plenificando de sentido a vida dos indivíduos nos tempos hodiernos, dando-lhes uma direção e servindo de guia para suas ações, já que todas as outras instituições, principalmente as políticas, estão cada vez mais desacreditadas, fazendo com que os indivíduos se sintam cada vez mais desamparados, angustiados, inseguros, infelizes e à beira da depressão psíquica e cognitiva (GAULEJAC, 2007). 
Elaboram conceitos heurísticos como "homem-empresa", instituição escolar como “organização escolar" flexível - isto porque ajustada segundo as necessidades do mercado e segundo seus preceitos, uma organização "produtiva" (preparação do capital humano com as competências e habilidades requeridas pela base técnica-material da produção capitalista) e de serviços -, "empresa de si”, "empreendedor de si”, servindo como sinalizações para o cultivo e o desenvolvimento de atitudes, comportamentos (racionais) e sentimentos (afetivo/emocional) a serem aprendidos, copiados, internalizados e reproduzidos em todos os âmbitos da vida social, públicos e privados.

Erudição e cultura não produzem rentabilidade, muito menos, competitividade. O saber requerido e que realmente importa é aquele ligado à prática (pragmático, utilitário, instrumental), o saber-fazer, e exige que o indivíduo esteja aberto, disposto e apto a "aprender a aprender" "ao longo de toda a vida". Afinal, "o mercado é um processo de aprendizagem contínua e adaptação permanente" (DARDOT; LAVAL, 2016, p. 147).

As organizações empresariais necessitam, mais do que em qualquer outro momento histórico, que os trabalhadores se submetam, sem resistência e rebeldia, às novas exigências e incertezas do mercado de trabalho, como também, às demandas das relações de trabalho toyotizadas.

Para isso, precisarão investir nos estudos de manipulação da subjetividade (desejos, sentimentos, energia psíquica, criatividade, imaginação, afetividade etc.) do trabalhador ${ }^{5}$, obtendo sua subsunção e exploração consentidas e consensuais ${ }^{6}$. Na verdade, há um refinamento desse processo de sedução e ludibriar, reforçado pelo discurso da competitividade econômica mundial e pelas perdas dos direitos e da proteção social dos trabalhadores ${ }^{7}$.

Procura-se seduzir os indivíduos garantindo sua galvanização pelos segredos do sucesso, da satisfação dos desejos, dos resultados, do desempenho eficaz, da competitividade e da concorrência, de modo que fiquem cada vez mais fascinados por acrobacias do "aprender a aprender" do que por conteúdos. No mundo do mercado e dos negócios, o essencial é ser pragmático e guiar-se por boas práticas, e não por teorias.

\footnotetext{
${ }^{5}$ Ver o filme $A$ Onda, da década de 1980 e não a nova versão.

6 “"...] a dimensão subjetiva tornou-se tanto uma realidade em si como um instrumento objetivo de sucesso da empresa. A 'motivação' no trabalho apareceu, então, como o princípio de uma nova maneira de conduzir os homens no trabalho, mas também os alunos nas escolas, os doentes nos hospitais e os soldados no campo de batalha. A subjetividade, feita de emoções e desejos, paixões e sentimentos, crenças e atitudes, foi vista como a chave do bom desempenho das empresas. Departamentos de recursos humanos, empresas de seleção e recrutamento e especialistas em formação puseram em ação um trabalho específico de conciliação entre a subjetividade desejante e os objetivos da empresa". (DARDOT; LAVAL, 2016, p. 359)
}

${ }^{7}$ No Brasil são elucidativas a Reforma Trabalhista e a Reforma da Previdência. 
A pedagogia da gestão gerencialista traduzida seria: como conduzir o trabalhador e envolvếlo com os objetivos da empresa, manipulando-o e controlando-o de modo perspicaz, obliterando as formas de controle e poder a que está indiscutivelmente preso (prisão que liberta), extraindo desses trabalhadores uma implicação subjetiva e afetiva com seu trabalho ${ }^{8}$. É assim que "a repressão é substituída pela sedução, a imposição pela adesão, a obediência pelo reconhecimento, [...] desejo de sucesso, gosto pelo desafio, necessidade de reconhecimento, recompensa pelo mérito pessoal" (GAULEJAC, 2007, p. 113).

Os próprios trabalhadores se autocontrolam, autodisciplinam, autovigiam, através dos resultados que precisam alcançar (eliminam-se, assim, as funções intermediárias de supervisores, por exemplo); do desempenho, sempre mais alto e melhor, que precisam demonstrar; redobram a atenção para evitar as falhas e fazer certo da primeira vez, para agir de modo eficiente, seguindo à risca o paradigma utilitarista, procurando "otimizar a relação entre os resultados pessoais de sua ação e os recursos que a isso consagra" (GAULEJAC, 2007, p. 77), fazendo mesmo cada vez mais com sempre menos (meios e salário).

Pode-se elencar como algumas das características principais da gestão gerencialista, além do "primado dos objetivos financeiros, a produção da adesão (e) a mobilização psíquica" (GAULEJAC, 2007, p. 112). De modo que

o poder gerencialista não funciona como uma 'maquinaria' que submete indivíduos a uma vigilância constante, mas como um sistema de solicitação que suscita um comportamento reativo, flexível, adaptável, capaz de por em prática o projeto da empresa. [...] A gestão gerencialista prefere a adesão voluntária à sanção disciplinar, a mobilização à obrigatoriedade, a incitação à imposição, a gratificação à punição, a responsabilidade à vigilância. [...] Não se procura mais indivíduos dóceis, mas 'batalhadores', winners que têm gosto pelo desempenho e pelo sucesso, que estão prontos para se devotar de corpo e alma. Duas outras qualidades também são exigidas: o gosto pela complexidade e a capacidade de viver em um mundo paradoxal. (GAULEJAC, 2007, p. 118-119-120)

Instala-se um clima de pressão contínua dentro e fora do ambiente de trabalho. As fronteiras entre os locais e postos de trabalho, entretenimento e família se dissipam, ainda mais com a utilização massiva das novas tecnologias de comunicação e informação que possibilitam estar ligado ininterruptamente, transgredindo as barreiras de espaço e de tempo pela hegemonia do ciberespaço.

As expectativas dos empregadores aumentam no que se refere aos resultados, ao desempenho. O trabalhador se vê obrigado e forçado, pelas próprias circunstâncias da economia, a estar sempre acima das projeções, pois só assim poderá se manter por mais tempo empregado,

${ }^{8}$ Ver a animação Monstros $S / A$. 
embora não seja possível prever o quanto, porque com a instalação da concorrência brutal entre os trabalhadores e o processo de individualização que essas tecnologias gerenciais geram, o "sempre mais", "sempre melhor", a "inovação" e a "reatividade" nunca parecem ser suficientes, sendo inundado e tendo de conviver com um sentimento de angústia. Afinal, "o sucesso pode ser apenas temporário em um universo em que a competição obriga a proezas constantemente renovadas" (GAULEJAC, 2007, p. 231) e nenhum ser humano é um poço infinito de imaginação e criatividade.

Essas técnicas da gestão gerencialista estão bem presentes nas práticas de Jorge Paulo Lemann e de seus dois principais discípulos: Marcel Herrmann Telles (Marcel Telles) e Carlos Alberto Sucupira (Beto Sucupira). Metas grandes, arriscadas e audaciosas; cultura meritocrática ${ }^{9}$ com incentivos para aqueles que apresentarem desempenho excepcional; busca por pessoas fanáticas, obsessivas com o trabalho ${ }^{10}$; corte e controle de custos inclemente; arriscar; sonhar grande; "uma dose de pressão que nem todos podem aguentar" (CORREA, 2013, p. 36); bônus ${ }^{11}$; estímulo à competição interna; avaliação; ser resiliente; aprender com o melhor e replicar; copiar o que já deu certo e é o melhor; padronização dos processos e procedimentos de trabalho; melhoria contínua.

É possível inferir, a partir desse quadro, o perfil de trabalhador procurado por Lemann, o tipo específico de profissional que o próprio denominou com a sigla "PSD: Poor, Smart, Deep Desire to Get Rich (pobre, esperto, com grande desejo de enriquecer)" [...], que tenha “"faca no dente' e "brilho no olho"' (CORREA, 2013, p. 53-69).

A gestão gerencialista, seu ethos, o novo consenso que produz, enfim, essa nova paideia, é a nova doença social do século XXI, ou, como intitula Gaulejac (2007), a "gestão como doença do social". Chega-se mesmo, ao cúmulo de se considerar o estresse como um dado positivo, pois exerce uma pressão benéfica (estímulo) para que o trabalhador faça mais e melhor com menos, favorecendo o desempenho.

[...] a "resistência ao estresse" é exigida como uma qualidade necessária para ter sucesso. Mais do que se interrogar sobre suas causas, aprende-se a "gerenciá-lo". Essa gestão consiste em acostumar-se com ele por meio de exercícios ou de truques: relaxamento das espáduas, respiração ventral, relaxamento, meditação, massagens, bolas de borracha "antiestresse", caixa que permite medir as capacidades de resistência etc. Nesse domínio, a imaginação dos experts não tem

\footnotetext{
9 "Os três sócios acreditam que as melhores pessoas anseiam pela meritocracia, enquanto as pessoas medíocres têm medo dela”. (COLLINS, 2013, p. 10)

10 “As pessoas obcecadas não se tornam as mais populares, já que com frequência intimidam as outras. Mas, quando os fanáticos se reúnem com outros fanáticos, o efeito multiplicador é irrefreável”. (COLLINS, 2013, p. 12)

11 “[...] os bônus podiam chegar a quatro ou cinco salários extras, [...] desde que os funcionários batessem suas metas. Era uma regra clara e simples que valia até mesmo para os office boys: trabalhe bem e você será recompensado. Para Jorge Paulo era fundamental que todos, desde a base, se sentissem ‘donos' daquele negócio. Só assim dariam o melhor de si e fariam a instituição crescer. Para incentivar ainda mais o pessoal, os bônus eram pagos duas vezes ao ano". (CORREA, 2013, p. 57)
} 
limites. [...]. Eles o consideram como um mal necessário, ao qual é conveniente se adaptar, canalizando seus efeitos mais nocivos. [...] [No entanto], as múltiplas técnicas para aprender a gerenciar seu estresse só podem mantê-lo, pois é o próprio modo de gestão que é responsável por ele. (GAULEJAC, 2007, p. 225299)

Essa gestão gerencialista mina a solidariedade, o ambiente saudável, as relações amistosas, de companheirismo, cooperação, partilha, proximidade, consciência de classe entre os trabalhadores, despolitizando-os ou repolitizando-os, segundo os preceitos neoliberais. Outros sentimentos, relações degenerativas e pérfidas afloram, como a violência, sendo uma delas a manifestação de assédio e suas variações, que terminam se banalizando; a degradação das condições de trabalho e sua intensa precarização; a competição generalizada com a estigmatização dos perdedores como incompetentes, incapazes, fracassados; o prejuízo feito a si próprio e os estratagemas preparados para derrubar o outro, a fim de se alcançar as metas, os objetivos; e por aí afora.

[...] quando cada um quer ser campeão, ninguém mais se preocupa com o bem comum. A vida não tem mais outro sentido a não ser ultrapassar os outros e não se deixar ultrapassar. A perversão da concorrência começa no momento em que o homem acredita que, para ser o melhor, ele deve ser o primeiro. [...] (Desta feita, cria-se uma) ilusão de onipotência. Cada indivíduo, persuadido no fundo de si mesmo de que é o melhor, adere a uma cultura de competição, que celebra o mérito individual. Seguro de ser vitorioso, ele não vê que, afinal de contas, os perdedores serão sempre mais numerosos do que os ganhadores, e que o custo da vitória é elevado. (A alienação extrema em que se encontra) produz cegueira sobre as oportunidades reais de sucesso, assim como a exigência de sucesso contínuo leva obrigatoriamente ao fracasso. $\mathrm{O}$ afastamento dos que possuem menor desempenho leva à exclusão dos mais idosos, dos mais fracos, dos recalcitrantes e, afinal de contas, de todos aqueles que se esgotam. (GAULEJAC, 2007, p. 174-233-234)

A tendência é o trabalhador se extenuar pela sobrecarga de trabalho, pressão incessante, responsabilização e individualização ${ }^{12}$ as quais é exposto e lhe são impostas. Não se deve esquecer que a gestão gerencialista trabalha sob o princípio da racionalidade econômica, tendo como principais pilares, o "pragmatismo, utilitarismo, competição, (a) rentabilidade, eficácia, (o) desejo de ganhar e de poder" (GAULEJAC, 2007, p. 184). Intensifica-se, cada vez mais, a pressão do número e dos instrumentos de medida, pois se a eficiência se mede pela utilidade da ação e o quanto se é capaz de produzir mais com menos e nem por isso deixando de apresentar excelentes

\footnotetext{
12 "Os médicos do trabalho são cada vez mais numerosos, demonstrando a ligação entre as novas formas de organização do trabalho e o agravamento das perturbações de saúde dos trabalhadores. [...] O estresse, a ansiedade, o esgotamento profissional são tratados em nível individual em seus efeitos psíquicos ou psicossomáticos, com o auxílio de psicólogos e psiquiatras. A empresa externaliza desse modo as consequências da violência das relações de trabalho que ela gera". (GAULEJAC, 2007, p. 226-314)
} 
resultados, a eficácia se define como o "reino da medida e da quantificação" (LAVAL, 2004, p. 197).

Logo, compreender é "modelar, isolando certo número de variáveis e de parâmetros, que podemos então medir” (GAULEJAC, 2007, p. 71). Não se trata de usar a razão, mas sim, de fazer uma racionalização ${ }^{13}$ (instrumentalização da razão) dos processos e procedimentos organizacionais e funcionais do trabalho de forma objetiva (matemática, contábil e estatisticamente), testados pela prática (experiência) pragmática/utilitarista. Como diz Laval (2004, p. 207), "a eficácia é sempre mensurável" podendo "ser relacionada a dispositivos, a métodos e técnicas inteiramente definidas, padronizadas e reprodutíveis em grande escala, com a condição, todavia, de uma 'formação', de uma 'profissionalização', de uma 'avaliação' e de um controle dos serviços de execução”.

A mensuração favorece a ilusão de "coerência da organização, a homogeneização das práticas e dos processos de avaliação" (GAULEJAC, 2007, p. 105). Abordagem experimental (práticas) e objetivista, utilitarismo, racionalidade instrumental e economismo ${ }^{14}$ são os princípios da quantofrenia e da abordagem da gestão gerencialista.

A busca por uma maior racionalização dos meios leva à valorização dos critérios econômicos e financeiros em detrimento das finalidades sociais e humanas, cada vez mais desvalorizadas. "A colocação da ação como valor leva a desconsiderar os valores como guia para a ação” (GAULEJAC, 2007, p. 281).

Hoje, "o projeto para (e de) cada indivíduo é o de ganhar e de aproveitar o mais possível" (GAULEJAC, 2007, p. 165), concentrando-se no presente, uma vez que perdeu-se o elo com o passado (função política, ética e social da educação) e a esperança - que tem o potencial de se transformar em esperançar - na possibilidade de um outro futuro.

As novas práticas da gestão gerencialista fomentam a transformação do homem em capital humano e flexível. O capital humano é "um bem privado proporcionando uma remuneração ao indivíduo que o tem", sendo estrita e extremamente individualista: "o indivíduo possui recursos próprios que ele vai tentar fazer crescer ao longo de sua existência (eterno aprendiz que aprende ao longo de toda a vida) para aumentar sua produtividade, sua renda e suas vantagens sociais". (LAVAL, 2004, p. 27) (o parênteses é nosso).

\footnotetext{
13 “A racionalização é [...] um mecanismo de defesa que, sob as aparências de um raciocínio lógico, tende a neutralizar aquilo que é perturbador, aquilo que incomoda, aquilo que não entra em 'sua' lógica. Nesse sentido, a racionalização está do lado do poder, ao passo que a razão está do lado do conhecimento. Este último não deve submeter-se a um princípio de eficácia, e sim a um princípio de pesquisa do sentido. Ora, sob muitos pontos, a eficiência se opõe ao sentido". (GAULEJAC, 2007, p. 73)

14 “[...] faz com que o pessoal seja levado em conta como uma variável de ajustamento diante das exigências do mercado”. (GAULEJAC, 2007, p. 139)
} 
No tocante à flexibilização, as relações e condições de trabalho são desregulamentadas. Para os trabalhadores isso significa: "deslocamento, horários irregulares, trabalho noturno, desorganização da vida familiar e de seus ritmos biológicos" (GAULEJAC, 2007, p. 61). Em outras palavras, precarização e precariedade das condições de trabalho e da reprodução das condições materiais de existência. Para os empresários e homens de negócio, o resultado é maior competitividade no mercado nacional e internacional.

A valorização da concorrência e da empresa se torna a forma geral de ser da sociedade. $O$ homem-empresa, segundo Dardot; Laval (2016, p. 140), aspira, ainda que vagamente, a uma condição melhor, sendo impelido a destinar energias e recursos à melhoria da própria situação. Para isso, necessita tornar-se "empreendedor" e ao empreender vai aprender e "aprender a aprender", porque o próprio mercado, o jogo da competição, da concorrência, da busca das oportunidades, do ganho e do lucro constitui um processo de formação.

Em situação de mercado, o indivíduo necessita de um determinado tipo de conhecimento contrário ao científico (patrimônio histórico-cultural acumulado e decantado pela humanidade), que não se refere ao porquê, mas ao quanto. Trata-se, portanto, do conhecimento "que um indivíduo pode adquirir em sua prática, e cujo valor só ele pode avaliar; o conhecimento que ele pode utilizar de maneira proveitosa para vencer os outros na competição" (DARDOT; LAVAL, 2016, p. 143).

Esses conhecimentos individuais e particulares são uns dos mais importantes ou, em todo caso, são mais eficazes que os dados estatísticos agregados, na medida em que permitem a realização de todas as pequenas mudanças permanentes às quais o indivíduo deve adaptar-se no mercado. [...] Apenas as motivações individuais impelem os indivíduos a fazer o que devem fazer, sem que ninguém tenha de lhes dizer para fazê-lo, utilizando conhecimentos que eles são os únicos a deter ou buscar. (DARDOT; LAVAL, 2016, p. 144)

Gaulejac (2007, p. 78) (os parênteses são nossos) é ainda mais esclarecedor e enfático:

O pensamento é considerado como inútil se não permitir contribuir para a eficácia do sistema. [...] A pertinência do conhecimento é medida (afinal, só tem valor aquilo que puder ser objetivamente observado, experimentado, mensurado. O empirismo é o único método válido) pelo metro de sua utilidade para a organização. [...] Podemos exercer a liberdade de pensamento e de palavra, com a condição de que essa liberdade sirva para melhorar os desempenhos. Aquele que levanta um problema sem trazer sua solução é percebido como alguém que perturba, um ser negativo, ou até um contestador, que é melhor eliminar (porque pode contagiar os outros). O conformismo é a contrapartida do utilitarismo. O único critério reconhecido como dando sentido é o critério de utilidade. A questão não é mais, então, produzir conhecimento em função de critérios de verdade, mas segundo critérios de eficiência e de rentabilidade dos objetivos fixados pelo sistema. 
Esse homem-empresa adquire seu valor não mais tanto por um diploma, já que o mercado de trabalho é incerto, volátil e flutua, segundo as vicissitudes da economia mundial, estando cada vez mais desregulado e flexibilizado. Importa muito mais as competências desenvolvidas, que correspondem, conforme Thomas F. Gilbert (1978), aos saberes práticos que solucionam os problemas e criam ótimos resultados.

Mediante a teoria da competência, o comportamento deve ser entendido como meio para um fim e não como fim em si mesmo, o que significa que "pessoas competentes são aquelas que podem criar resultados valiosos sem o uso excessivo de comportamentos dispendiosos" (GILBERT, 1978, p. 17), porque o que realmente importa é a performance, o desempenho e estes podem e devem ser reforçados através de premiação. As deficiências no desempenho, portanto, podem ser corrigidas e aperfeiçoadas pelo sistema de gestão (GILBERT, 1978, p. 76).

Uma das características da competência que vale a pena ressaltar é que ela produz uma maior individualização das relações sociais, mina a solidariedade e o companheirismo entre os trabalhadores, é indiferente aos direitos sociais, gera o isolacionismo e o individualismo nos indivíduos e deteriora o percurso profissional do trabalhador. "O empregador compra, sobretudo, um 'capital humano', uma 'personalidade global' combinando uma qualificação profissional stritu sensu, um comportamento adaptado à empresa flexível, um gosto pelo risco e pela inovação, um engajamento máximo na empresa, etc” (LAVAL, 2004, p. 57).

Eis o significado de se desenvolver e reiventar como homem-empresa, fazendo da empresa mais do que um modelo a imitar, mas uma atitude a adquirir e desenvolver, reforçada e verificada pelos procedimentos de avaliação, mensurando, objetivamente, desempenhos e resultados. “[...] o indivíduo não deve mais se ver como um trabalhador, mas como uma empresa que vende um serviço em um mercado" (DARDOT; LAVAL, 2016, p. 335).

Para além, esse homem-empresa é, em primeiro lugar, um empreendedor de si. O empreendedor "é um ser dotado de espírito comercial, à procura de qualquer oportunidade de lucro que se apresente e ele possa aproveitar, graças às informações que ele tem e os outros não. Ele se define unicamente por sua intervenção específica na circulação de bens" (DARDOT; LAVAL, 2016, p. 145). É capaz de descobrir e detectar boas oportunidades e busca sempre testar suas faculdades, aprender, corrigir-se, adaptar-se, fazendo das relações mercantis um processo de formação de si.

“O espírito que ele desenvolve é o da especulação, que mistura risco e previsão. [...] Aprender a procurar informação torna-se uma competência vital” (DARDOT; LAVAL, 2016, p. 146). A aquisição da informação que favorece a ação é propiciada pelo processo concorrencial e 
empresarial, o que permite concluir que "apenas pelo jogo do mercado nós nos educamos a nos governar como empreendedores" (DARDOT; LAVAL, 2016, p. 146).

Peter Drucker, figura reconhecida no management, defende e propaga a necessidade de criação de uma “sociedade de empreendedores”, caracterizada “por sua 'adaptabilidade' e sua norma de funcionamento, a mudança perpétua: 'O empreendedor vai buscar a mudança, ele sabe agir sobre ela e explora-la como uma oportunidade"'. Além disso, a

nova "gestão de empreendedores", tal como o define Drucker, pretende espalhar e sistematizar o espírito de empreendimento em todos os domínios da ação coletiva, em particular no serviço público, fazendo da inovação o princípio universal de organização. Todos os problemas são solucionáveis dentro do "espírito da gestão" e da "atitude gerencial"; todos os trabalhadores devem olhar para sua função e seu compromisso com a empresa com os olhos do gestor. [...] A educação e a imprensa serão requeridas para desempenhar um papel determinante na difusão desse novo modelo humano genérico. [...] a Organização para a Cooperação e Desenvolvimento Econômico (OCDE) e a União Europeia, sem se referir explicitamente aos focos de elaboração desse discurso sobre o indivíduo-empresa universal, serão continuadoras poderosas deles, por exemplo, tornando a formação dentro do "espírito de empreendimento" uma prioridade dos sistemas educacionais nos países ocidentais. (DARDOT; LAVAL, 2016, p. 154-155)

O "espírito empreendedor" e a atitude/conduta empreendedorista se transformam em questão de sobrevivência para os trabalhadores, que, com isso, tornam-se ainda mais dependentes das demandas do capital e dos capitalistas. A ilusão de que todos podem ser empreendedores serve aos propósitos da competição e da busca por melhores resultados, um verdadeiro "salve-se quem puder", onde cada vez mais os trabalhadores se veem forçados a internalizar e vivenciar as novas normas, regras, processos, procedimentos e exigências do mercado. Sendo assim, a grande novidade da gestão gerencialista, da empresa de si mesmo, do empreendedor de si, do especialista em si mesmo, do empregador de si mesmo, do inventor de si mesmo,

reside na modelagem que torna os indivíduos aptos a suportar as novas condições que lhe são impostas, enquanto por seu próprio comportamento contribuem para tornar essas condições cada vez mais duras e mais perenes. Em uma palavra, a novidade consiste em promover uma "reação em cadeia", produzindo "sujeitos empreendedores" que, por sua vez, reproduzirão, ampliarão e reforçarão as relações de competição entre eles, o que exigirá, segundo a lógica do processo autorrealizador, que eles se adaptem subjetivamente às condições cada vez mais duras que eles mesmos produziram. (DARDOT, LAVAL, 2016, p. 329)

Esse é o verdadeiro intento das Fundações e Institutos, como é o caso da Fundação Lemann, criada em 2002, embora o objetivo amplamente propalado seja outro, como divulgam os meios de comunicação de massa, onde a grande preocupação aparece como sendo a melhoria da qualidade 
da Educação Básica e a construção de um país "em que todos têm oportunidades de estudar e chegar lá" (O próximo sonho grande de..., NaPrática.Org, 2016).

Para o empresário (Jorge Paulo Lemann), a construção de uma nova cultura “não acontece do dia para a noite. Demora mais de 10 anos até que os primeiros trainees pratiquem o que aprenderam, ganhem experiência e estejam prontos para formar a próxima geração" (As lições de gestão de..., Revista Exame, 2014). Aparece, aqui, um dado importante no que concerne à importância que a educação adquire para os homens de negócio na nova fase da gestão gerencialista do capital: é preciso tomar conta - gerir - da formação inicial da juventude.

Melhor do que criar um governo para os empresários, banqueiros e homens de negócio em geral e um Estado reformado que subsidie as suas transações e os interesses do mercado, é incutir certos "valores" na juventude que, quem sabe, pode vir a governar o país, perpetuando a dominação e a direção do capital em todos os domínios da vida social, sem distinção entre público e privado, até mesmo porque a tendência prescrita é a extinção desse primeiro. Nas palavras de Lemann:

Hoje existe muita oportunidade para gente jovem fazer parte da política e da governança do país, e espero que esses jovens introduzam nossos princípios de meritocracia, resultados, empreendedorismo [...]. Uma administração mais pragmática e com bom senso poderia melhorar o Brasil enormemente. Essa é minha grande esperança. (O próximo sonho grande..., NaPrática.Org, 2016)

Quanto mais cedo o espirito de empresa e de empreendedorismo for internalizado e reproduzido pelos próprios indivíduos, maior a possibilidade de sucesso do projeto político-social-econômico do empresariado e dos homens de negócio, fabricando o trabalhador flexível, eficiente, eficaz, produtivo, reativo, inovador, pronto a se adaptar às mudanças, às incertezas do mercado em geral e do mercado de trabalho em particular, assumindo as responsabilidades individualmente pelos riscos inerentes a suas escolhas. De quebra, transformam a educação em um belo filão de mercado.

Jorge Paulo Lemann aparece como o ícone e modelo a ser imitado por todos aqueles que desejam chegar ao sucesso, aprender por toda a vida, colocar em primeiro lugar o saber pragmático, útil em detrimento do conhecimento enciclopédico e erudito sem utilidade prática. Afinal, Lemann nunca se considerou um estudioso, preocupado em analisar demais as coisas: “[...] pessoas muito preparadas (fazem milhões de análises e estudos) podem deixar de fazer coisas grandes porque estudam demais e com isso não se arriscam" (Lemann tem um conselho para quem busca..., Revista Exame, 2017).

Mais uma vez, fica evidente que os conhecimentos e os saberes que verdadeiramente importam são os práticos, úteis e não os teóricos, pois são eles que podem contribuir para a 
adaptação do indivíduo "às reviravoltas do mundo além da sala de aula" (Lemann tem um conselho para quem busca..., Revista Exame, 2017).

Nessa nova conjuntura, as organizações empresariais, os homens de negócio, passam a expandir e estender seus domínios, fazendo do mundo a sua imagem e semelhança, remodelando o ethos da vida social (disseminando uma nova paideia) por intermédio do "imperativo da concorrência, da maximização dos lucros e da acumulação, que inevitavelmente exigem a colocação do valor de troca na frente do valor de uso e do lucro na frente das pessoas" (WOOD, 2014, p. 24).

O mercado, os interesses privados e a lógica empresarial que os traduz passam a regular, gestar e gerir todas as relações sociais e de produção, incluindo o campo das políticas "públicas"estatais. O crescimento da influência dessas organizações e corporações, dos empresários e dos homens de negócio materializa-se através do Todos Pela Educação, movimento de caráter global com suas representações na escala nacional, interferindo diretamente nas políticas "públicas" dos Estados-Nação, principalmente no âmbito da educação.

É assim que a lógica empresarial vai se apropriando e tomando conta da educação "pública"-estatal e construindo um novo ideal de homem e de sociedade (nova paideia): o capital humano, a sociedade de mercado. Se desde a Revolução Industrial do século XVIII, as relações entre complexo do trabalho/produção e complexo da educação/escola já eram denunciadas, essas relações tornaram-se ainda mais complexas, de modo que hoje assiste-se à entrega da educação "pública"-estatal (rendida e prisioneira em uma gaiola dourada) ao mercado, aos empresários e homens de negócio.

A política "pública"-estatal educacional e a educação "pública"-estatal passam a funcionar sob a lógica da gestão gerencialista empresarial ou, em outras palavras, pela lógica do mercado e da prevalência dos interesses individuais, onde os processos e os procedimentos são organizados seguindo os parâmetros do léxico e do ethos dos homens de negócio, devendo: apresentar resultados, desempenho; realizar projetos; primar pela "qualidade" quantificada (IDEB); desenvolver boas práticas; alcançar as metas; desenvolver o perfil do novo homem para o mercado (flexível, reativo, comunicativo, empreendedor de si - homem-empresa -, motivado, eficaz, adaptável, competitivo, autônomo, etc.); e todas as demais práticas implicadas nas organizações produtivas e de serviços, de modo que a educação vai deixando de atuar como uma instituição e passa a se comportar como uma organização produtiva flexivel (de bens e serviços).

A empresa e os "homens de empresa" tomam o lugar da religião, das instituições políticas (partidos, sindicatos), da própria sociedade (Durkheim), e criam a nova ética, a nova moral, o novo 
consenso para a coesão social, pavimentando o caminho para o neoliberalismo. No caso do Brasil, um neoliberalismo social-liberal de Terceira Via à brasileira.

Os conceitos, as ideias, os valores, as atitudes, os comportamentos e os sentimentos da lógica empresarial e dos homens de negócio, personificações do sistema capital, devem se tornar o referencial para repensar e reformar a Educação Básica e a superior. Num movimento globalmente planejado, os empresários e os homens de negócio se lançam no processo de apropriação da educação da força de trabalho dos filhos da classe trabalhadora, contando com a pressão dos Organismos Multilaterais Internacionais, principalmente com o Banco Mundial (o Ministério Mundial da Educação, como assevera Leher (1998)).

Isto explica o objetivo do Banco Itaú, através do Instituto Unibanco, com o Projeto Jovem de Futuro destinado às escolas da rede pública, estaduais e municipais, voltado ao Ensino Médio. O Futuro para os filhos da classe trabalhadora e camadas populares é o setor da informalidade e de serviços e mesmo assim, os postos de trabalho não são para todos, mas apenas para aqueles que apresentam futuro, assimilando, seguindo e reproduzindo a paideia empresarial, dos homens de negócio e do sistema de mercado.

A imbricação entre princípios, preceitos, prescrições, práticas empresariais e filosofia dos homens de negócio com o processo de escolarização e de formação da força de trabalho demonstra o grau de confluência alcançado entre as esferas da produção (economia), da política, dos valores éticos-morais-culturais (ideoculturais), influenciando e condicionando a forma das relações sociais e de produção entre os indivíduos sociais, tornando-se guia para as ações e interações sociais, evidenciando o grau de complexidade das determinações reflexivas que vão aprofundando os nexos e conexões entre produção, mercado, trabalho, capital, Estado e formação da força de trabalho (educação).

Em resposta às novas e renovadas necessidades do processo de produção capitalista, das permanentes mudanças no processo e organização do trabalho - que impõe novas exigências para a formação da força de trabalho -, do aperfeiçoamento das maneiras de subsunção e controle do trabalho pelo capital e captura da subjetividade-afetividade dos trabalhadores, realiza-se inovações que imiscuem controle com flexibilidade, adestramento com consentimento, subserviência/submissão com resistência.

Embora captadas como contradições, são a concretização das mudanças incorporadas na organização do processo e dos procedimentos produtivos e de trabalho, múltiplas determinações de uma totalidade sociometabólica em essência contraditória, que confunde àqueles que se enredam nas aparências do real, estando momentaneamente incapacitados de construir as mediações e nexos causais entre fenômenos que parecem distintos, mas que, na verdade, são contrários que se 
complementam. Nesse contexto, fordismo, taylorismo, toyotismo se complementam, através da superação por incorporação de elementos dos antigos processos e procedimentos de organização da produção e do trabalho pelos novos.

Por isso, não se trata, pois, apenas de uma nova racionalidade como abordam Dardot; Laval (2016). A racionalidade é a mesma: a do capital e sua lógica expansiva e acumulativa; porém, sob novos envoltórios, novas formas, objetivando aperfeiçoar os mecanismos de controle, de dominação para obtenção de consenso do social para a formação do novo senso comum, viabilizando, assim, pôr em marcha o novo projeto de futuro (sombrio para a classe trabalhadora e seus filhos) desenhado pelo empresariado e pelos homens de negócio, pela burguesia nacional e pela grande burguesia internacional e seu bloco no poder, exercendo a supremacia através das regulações, prescrições, regulamentações, condicionamentos e condicionalidades disseminadas pelos seus Organismos Multilaterais Internacionais, pelos Estados Nacionais, sendo, todos, enfim, a personificação do capital global em seu estágio fictício supremo.

O centro de comando político do sistema capital é o Estado-Nação e os Organismos Multilaterais são os co-gestores desses Estados Nacionais, alinhando-os com as renovadas necessidades do mercado capitalista e do metabolismo sistêmico do capital. Os ajustes e as reformas irão corresponder ao papel desempenhado por cada um dos Estados Nacionais no processo de produção e reprodução capitalista, na divisão internacional do trabalho, na extração de mais-valia absoluta e relativa, na expansão e na acumulação de capital, de modo que países centrais e países periféricos, embora sob a regência da mesma batuta, serão requisitados a realizar ajustes e reformas em grau e intensidade diferenciados para atender a objetivos específicos do sociometabolismo sistêmico do capital.

Isso significa que a Organização Mundial do Comércio, o Banco Mundial, o Fundo Monetário Internacional, a Organização para a Cooperação e Desenvolvimento Econômico, dentre outros organismos multilaterais, garantirão que cada Estado Nacional, de acordo com seu posicionamento (lugar ocupado na divisão internacional, técnica, funcional, social, hierárquica do trabalho) e classificação (centrais ou periféricos), cumpra com a função e operação que lhe cabe. Assim, Europa, América Latina, Ásia, África, Oceania, América do Norte operam segundo suas particularidades, produzindo especificidades que terminam se complementando e perfazendo a unidade da diversidade da totalidade do sistema metabólico do capital.

Desta feita, aos periféricos (América Latina, África, por exemplo), mesmo que "em desenvolvimento" - como é o caso do Brasil, que devido à subalternidade e dependência, o permanente endividamento (crédito e financiamentos diversos) acaba tendo sua autonomia política e econômica reduzidas e tornadas caudatárias dos países centrais e do bloco de poder hegemônico 
- cabe adequar suas políticas "públicas"-estatais às agendas e receituários dos co-gestores e regentes da orquestra do sistema capital mundial: os Organismos Multilaterais Internacionais, o empresariado e homens de negócio, tendo a garantia da criação das condições infraestruturais pela estrutura do aparelho e aparato jurídico-político-administrativo-ideológico-militar dos Estados Nacionais, já que são eles, afinal, a "estrutura totalizadora de comando político do capital" (MÉSZÁROS, 2002, p. 119).

Isso significa que, por mais que as mediações políticas da luta de classes se façam presentes, através das relações de força e poder medidas em termos de consentimento e resistência, hegemonia e contra-hegemonia, considerando as relações entre o histórico, o estrutural e as especificidades do real pesquisado, ainda assim, a supremacia está no controle hegemônico realizado e mantido pelo capital e seu sistema metabólico.

\section{CONSIDERAÇÕES FINAIS}

Procurou-se demonstrar que, pela forma como as organizações empresariais e os homens de negócio passam a atuar, utilizando da pedagogia gerencialista, terminam por propagar uma nova (e determinada) visão de mundo, expandindo seus domínios e remodelando o ethos da vida social. Trata-se de uma nova paideia que vem estabelecendo um consenso, uma espécie de pensamento único em torno da lógica de mercado, da concorrência, da competitividade, enfim, das necessidades do processo de acumulação do capital, o qual requer um determinado perfil de homem e de trabalhador. Nesse sentido, os processos educativos devem propiciar as condições para que o espirito da empresa e do empreendedorismo seja internalizado e reproduzido pelo indivíduo trabalhador.

A entrada do empresariado na disputa pela agenda educacional, demarcada pela atuação das fundações e institutos, congrega, portanto, dois objetivos claros: a) o primeiro de formar um sujeito trabalhador flexível e adaptado às incertezas do mundo produtivo, assumindo a responsabilidade pelos riscos, mesmo diante de um mercado de trabalho que se caracteriza por uma tendência crescente à maior precarização e desregulamentação; e b) segundo, pelas novas oportunidades de negócio que se abrem no mercado educacional pelo acesso crescente aos fundos públicos.

Trata-se, portanto, de produzir a futura geração de homens-empresa, empreendedores (trabalhador autônomo), flexíveis, eficientes, produtivos, performáticos, cuja única preocupação seja "aprender a aprender", isto é, "saber fazer", fazer mais e melhor com menos, receptivos ao controle por desempenho e resultados e mesmo incapazes de pensar por si mesmos se não tiverem 
as normas, as metas, as prescrições, os objetivos e projetos que organizem e operacionalizem suas ações.

\section{REFERÊNCIAS}

As lições de gestão de Jorge Paulo Lemann. Revista Exame, Abril, 14 de fevereiro de 2014. Disponível em: < https://exame.abril.com.br/revista-exame/as-licoes-de-lemann/ > Acesso em: 22 out. 2019.

CASTELO, Rodrigo. O social-liberalismo: auge e crise da supremacia burguesa na era neoliberal. São Paulo: Expressão Popular, 2013.

COLLINS, Jim. Prefácio. In: CORREA, Cristiane. Sonho grande: como Jorge Paulo Lemann, Marcel Telles e Beto Sicupira revolucionaram o capitalismo brasileiro e conquistaram o mundo. Rio de Janeiro: Sextante, 2013. p. 07-15.

CORREA, Cristiane. Sonho Grande: Como Jorge Paulo Lemann, Marcel Telles e Beto Sucupira revolucionaram o capitalismo brasileiro e conquistaram o mundo. Prefácio de Jim Collins. Rio de Janeiro: Sextante, 2013.

DARDOT, Pierre; LAVAL, Cristian. A nova razão do mundo: ensaio sobre a sociedade neoliberal. São Paulo: Boitempo, 2016.

GAULEJAC, Vincent de. Gestão como doença social: ideologia, poder gerencialista e fragmentação social. Trad. Ivo Storniolo. Aparecida: Ideias \& Letras, 2007.

GEORGE, Susan. O Relatório Lugano: sobre a manutenção do capitalismo no século XXI. Apresentação Laymarte Garcia dos Santos. São Paulo: Boitempo, 2003.

GILBERT, Thomas F. Human competence: engineering worthy performance. New York: Mc Graw Hill, 1978.

JAEGER, Werner Wilhelm. Paideia: a formação do homem grego. Trad. Artur M. Parreira. 3. ed. São Paulo: Martins Fontes, 1995.

LAVAL, Christian. A Escola não é uma empresa: o neo-liberalismo em ataque ao ensino público. Trad. Maria Luiza M. de Carvalho e Silva. Londrina: Editora Planta, 2004.

LEHER, Roberto. Da Ideologia do Desenvolvimento à Ideologia da Globalização: a educação como estratégia do Banco Mundial para "Alívio" da Pobreza. 1998. Tese (Doutorado em Educação). Faculdade de Educação. Universidade de São Paulo, São Paulo, 1998.

Lemann tem um conselho para quem busca algo grandioso na carreira. Revista Exame, 15 de agosto de 2017. Disponível em: < https://exame.abril.com.br/carreira/lemann-tem-umconselho-para-quem-busca-algo-grandioso-na-carreira/ >. Acesso em: 22 out. 2019.

MÉSZÁROS, István. Para além do Capital: rumo a uma teoria da transição. Trad. Paulo César Castanheira; Sergio Lessa. São Paulo: Editora da Unicamp; Boitempo Editorial, 2002. 
NEVES, Lúcia Maria Wanderley (Org.). A nova pedagogia da hegemonia: estratégias do capital para educar o consenso. São Paulo: Xamã, 2005.

NEVES, Lúcia Maria Wanderley (Org.). Direita para o social e Esquerda para o Capital: intelectuais da nova pedagogia da hegemonia no Brasil. São Paulo: Xamã, 2010.

O próximo sonho grande de Jorge Paulo Lemann. NaPrática.Org, 22 de setembro de 2016. Disponível em: < https://www.napratica.org.br/o-proximo-sonho-grande-de-jorge-paulolemann/ >. Acesso em: 22 out. 2019.

WOOD, Ellen Meiksins. O Império do Capital. Trad. Paulo Cezar Castanheira. São Paulo: Boitempo, 2014. 